\title{
EL DISEÑO GRÁFICO CONFIGURADO A TRAVÉS DEL MARKETING ESTRATÉGICO APLICADO A LOS RESTAURANTES DE PRIMERA GATEGORÍA DE LA GIUDAD DE GUENGA
}

\author{
GRAPHIC DESIGN GONFIGURED THROUGH \\ STRATEGIG MARKETING APPLIED TO FIRST-GLASS \\ RESTAURANTS IN CUENCA
}

\author{
María Elena Castro Rivera \\ Universidad del Azuay - Ecuador
}

Ingeniera Comercial y Magíster en Administración de Empresas por la Universidad del Azuay, además ha desarrollado otros estudios de cuarto nivel obteniendo diplomas superiores en Educación Universitaria por Competencias, Intervención en Proyectos Sociales y Gerencia Estratégica del Desempeño Empresarial. Desde el año 2013 hasta la actualidad labora como Docente de la Universidad del Azuay, en las áreas de Marketing, Gestión y Emprendimiento. También ha desempeñado en esta Institución las funciones de Directora de Talento Humano y Coordinadora de Vinculación con la Colectividad por la Facultad de Ciencias de la Administración. Actualmente tiene a su cargo la dirección del Departamento de Bienestar Estudiantil y Admisiones. En complemento a sus labores administrativas y de docente desarrolla investigación en las áreas de Mercadotecnia y Responsabilidad Social Empresarial, producto de aquello tiene a su haber varias publicaciones para revistas y conferencias del medio. Entre otras actividades laborales María Elena Castro ha trabajado para empresas como Continental Tire Andina y el Grupo Cartopel S.A.I.

mcastror@uazuay.edu.ec 


\section{Jhonn Manuel Alarcón Morales \\ Universidad del Azuay - Ecuador}

Diseñador y Magíster en Comunicación y Marketing por la Universidad del Azuay y Cocinero Profesional por la Escuela de Gastronomía CECAEM. Candidato a Doctor en Diseño en la Universidad de Palermo en Buenos Aires, Argentina. Desde el año 2012 hasta la actualidad labora como docente de la Universidad del Azuay en las escuelas de Diseño Gráfico, Diseño de Productos y Creación Teatral en las cátedras de Taller de Diseño, Marketing, Publicidad, Emprendimiento y Gestión de Proyectos. También desempeña funciones como diseñador gráfico editorial en el Departamento de Comunicación y Publicaciones de la misma Universidad. Sus habilidades las desarrolló al trabajar para varias empresas de la ciudad y en varios emprendimientos en las áreas del diseño gráfico y la gastronomía. En la actualidad investiga y escribe sobre la interacción del diseño y la gastronomía llamada Food Design. Como profesional piensa que el diseño debe ser honesto y ético, y que aún falta mucho por hacer y también mucho por comer.

jalarcon@uazuay.edu.ec

\section{Eugenia Isabel Román Guillén Trabajadora independiente - Ecuador}

Licenciada en Ciencias de la Educación nacida en Cuenca-Ecuador. Próxima a obtener el título de Ingeniera Comercial. Cursó su licenciatura e ingeniería en la Universidad del Azuay. Durante varios años se ha dedicado a la docencia en Educación Básica. Actualmente se desempeña como técnica de inclusión en el plan de gobierno "Toda Una Vida". Además, se encuentra en espera de la sustentación de su tesis de grado en la carrera de Administración de Empresas, la misma que está enfocada en el marketing estratégico para restaurantes de primera categoría.

eugeniaromang@hotmail.com 


\section{Resumen}

El objetivo de la presente investigación es definir aspectos básicos a tener en cuenta en la configuración del diseño gráfico a través de considerar la información proveniente de una estrategia de marketing propuesta para los restaurantes de primera categoría de la ciudad de Cuenca. Se trata mostrar al diseño gráfico como herramienta principal para comunicar, atraer y fidelizar a clientes. La metodología de investigación empleada se basó en técnicas cualitativas y cuantitativas de recolección de datos. Como primer paso, para plantear las variables de diseño gráfico, se propuso un modelo para el manejo de las variables de marketing mix: precio, producto, promoción, posición, presencia física, personas y procesos, esta propuesta se basó en el análisis de la oferta gastronómica en la ciudad y se determinó que está compuesta por clientes que buscan conocer la cultura de un pueblo, relacionarse con similares y vivir experiencias sensoriales en ambientes estimulantes mediante acciones y emociones. El segundo paso es, considerar el estudio de marketing para configurar las acciones de diseño gráfico que apoyen y fortalezcan la imagen y las comunicaciones de los establecimientos gastronómicos, sobre todo en los que se refiere a promoción y presencia física.

\section{Palabras clave}

Diseño gráfico, marketing, restaurantes, primera categoría, imagen, estrategias.

\section{Abstract}

This research aims to define the necessary basic aspects in a layout of graphic design through considering the information coming from a marketing strategy that was offered to first-class restaurants in Cuenca. The idea was to show graphic design as a main tool in order to communicate, attract and build loyalty with customers. The research methodology used was based on quantitative and qualitative techniques for data collection. First, in order to retrieve the graphic design variables, a model was proposed to manage the marketing mix variables: price, product, promotion, position, physical presence, people and processes. This proposal was based on the analysis of the city gastronomic offer and it was determined that it was composed by clients who seek to learn about the culture of people, connect with others and live sensory experiences in stimulating environments through actions and emotions. The second step was to consider the marketing study for setting up actions of the graphic design that will support and strengthen the image and communication of the gastronomic establishments, especially in those related to promotion and physical presence.

\section{Keywords}

Graphic design, marketing, restaurants, first category, image, strategies. 


\section{Introducción}

La revista Vistazo (2015) informó que en el Ecuador el sector gastronómico representa el 30\% de los ingresos generados por el turismo internacional; esto equivale a 69.600 millones de dólares. Lo que muestra la importancia de este sector en el país, en general, y particularmente en la ciudad de Cuenca. En Ecuador, el sector gastronómico se encuentra dentro de la industria del turismo. De acuerdo con Fandos y Flavián (2011) "la gastronomía se está convirtiendo en una motivación de viaje cada vez más importante en nuestros días" (p.12), lo que indica que este es un sector con gran potencial de expansión. En cuanto al aporte económico de la gastronomía, los mencionados autores señalan que "el gasto en alimentación, comidas y bebidas es la tercera partida de gastos más importante del turista medio" (Fandos y Flavián, 2011, p.13). Dado esto, este sector está en la capacidad de cada vez atraer más clientes nacionales e internacionales.

Los restaurantes entendidos como una unidad comercial, son aquellos que basan sus actividades en una serie de procesos basados en la tecnología y la racionalización, que están en constante mejora, para lo cual busca la creación de una marca (Vallsmadella, 2002) y el planteamiento de una comunicación efectiva que impacte en sus consumidores.

A las personas nos agrada comer bien y en sitios atractivos, razón por la que un emprendedor debe considerar ambos aspectos. El local debe abordarse como un proyecto multidisciplinario encarado desde la visión de la arquitectura, pero en el que también estén presentes las competencias del diseño de interiores, industrial, de iluminación y diseño gráfico. Este último constituye una parte importante de la ambientación, pues no sólo se trata del trabajo con logotipos, sino que se involucra en elementos decorativos y detalles de la mesa, como platos, servilletas y manteles (Pérez, 2011).

Para atraer más clientes, incrementar las ventas y la rentabilidad en un restaurante es indispensable que el establecimiento ponga en consideración sus productos y servicios a su público objetivo a través de diferentes medios de promoción, integrar sus mensajes a los distintos canales de comunicación como la publicidad, la promoción de ventas, las relaciones públicas, el marketing directo, las ventas personales, las redes sociales, etc. Esto es lo que se conoce como CIM -Comunicaciones Integradas de Marketing-. En la mayoría de las CIM, el diseño gráfico puede convertirse en un aliado para comunicar los mensajes y fortalecer la estrategia de venta. Pierini (2011) manifiesta que, dentro del proceso de marketing, el proceso de diseño gráfico debe sostenerse mediante una metodología organizada basada en pasos coherentes, que también son responsabilidad del marketing, y que conduzcan a un resultado esperado. Para generar una imagen fuerte y reconocida de un restaurante, así como para obtener mejores resultados, se debe trabajar de manera conjunta distintas acciones del diseño gráfico, marketing de servicios y marketing sensorial. Lo más estimulante del diseño gráfico para restaurantes es la versatilidad de las aplicaciones. El concepto que surge de la base gastronómica es esencial. Diseñar para restaurantes es un ejercicio en el que se deja el ego de lado, porque la idea es complementar el trabajo arquitectónico desde lo gráfico. El éxito se logra cuando el comensal percibe el espacio como un todo coherente: imágenes y sabores (Pérez, 2011).

En manos del diseñador gráfico se encuentra el reto de investigar sobre lo que los propietarios del local tienen en mente y aportar todos los elementos creativos que se consideren necesarios. La gráfica se convierte en la presentación principal, debido a que en un restaurante el diseño gráfico abarca la selección de colores que constituirán la identidad gráfica y, de la mano con el diseño de interiores, aporta los elementos esenciales de lo que implica la experiencia de comer en determinado local. Cuando en un restaurante todo parece cuadrar a la perfección, más allá además de lo que el comensal es consciente o capaz de enunciar con palabras, la razón suele estar oculta detrás de un largo proceso asumido en equipo (Pérez, 2011). 


\section{Categorización del sector gastronómico según el Ministerio de Turismo}

Según Lloret (2012) el sector turístico y hotelero ecuatoriano en la actualidad tiene una tasa de crecimiento promedio anual de $4 \%$; lo que lo coloca como el cuarto ingreso dentro de la economía del país. Se sabe que el sector gastronómico forma parte de la industria de turismo; por lo que vale mencionar que la gastronomía es un significativo sector en crecimiento.

El Ministerio de Turismo es la institución que controla y regula las actividades turísticas en el Ecuador. El Departamento de Regulación y Control de cada zona de dicho Ministerio asigna una categoría a cada establecimiento gastronómico. Así, se han planteado cinco categorías de restaurantes: de lujo, primera, segunda y tercera categoría y de especialidades.

En el caso de los restaurantes de primera categoría, los parámetros exigidos por el Ministerio de Turismo son:

Instalaciones:

- Entradas: Entrada para los clientes, independiente de la del personal de servicio y mercadería.

- Vestíbulo: Con guardarropa, teléfono y servicios higiénicos independientes para hombres y mujeres.

- Comedor: Superficie, capacidad y categoría adecuadas al servicio.

- Cocina: Con elementos acorde a su capacidad, almacén, cámaras frigoríficas y cuartos fríos para carnes, pescados y verduras, mesa caliente, fregaderos, extracción de humo y olores.

- Mobiliario: Alfombras, lámparas, tapicería, vajilla, cristalería, mantelería y servilletas de tela acordes a la categoría.

- Aire acondicionado y/o calefacción.

- Ascensor: Si el establecimiento estuviese situado en cuarta planta o superior de un edificio.

- Escalera de servicio: Si el establecimiento tuviese más de una planta interior.

- Dependencias del personal de servicio:
Comedor, vestuarios, servicios higiénicos independientes para personal masculino y femenino.

Servicios:

- Carta de platos.

- Un primer grupo de entradas, con variedades y tres sopas o cremas.

- Un segundo grupo de verduras, huevos y fideos con cuatro variedades.

- Un tercer grupo de pescados con cuatro variedades.

- Un cuarto grupo de carnes y aves con cuatro variedades.

- Un quinto grupo de postres, compuesto de dulces, helados, quesos y frutas con cuatro variedades.

- Carta de vinos: Con cuatro variedades para cada grupo de vinos (blancos, rosados, tintos), licores, whiskys, cogñacs y champagnes. Así como aguas, cervezas, colas, refrescos, café e infusiones.

Personal:

- Un jefe de comedor con conocimientos del idioma inglés.

- Personal suficiente y uniformado, con estaciones de seis mesas por salonero. (Ministerio de Turismo, 2018)

Restaurantes de primera categoría de la ciudad de Cuenca

Díaz, Horacio \& Oyarzo (2017), comentan que las preferencias alimentarias tienen íntima relación con aspectos sociales, étnicos, religiosos, etc. En la ciudad de Cuenca, estos gustos se observan con una gran concurrencia de personas a los restaurantes de primera categoría. El gráfico 1 muestra que de los 870 restaurantes registrados en la ciudad de Cuenca en el Catastro Turístico 2018, tres restaurantes son de lujo, 50 son de primera categoría, 224 son de segunda, 451 son de tercera y 142 pertenecen a cuarta categoría. 


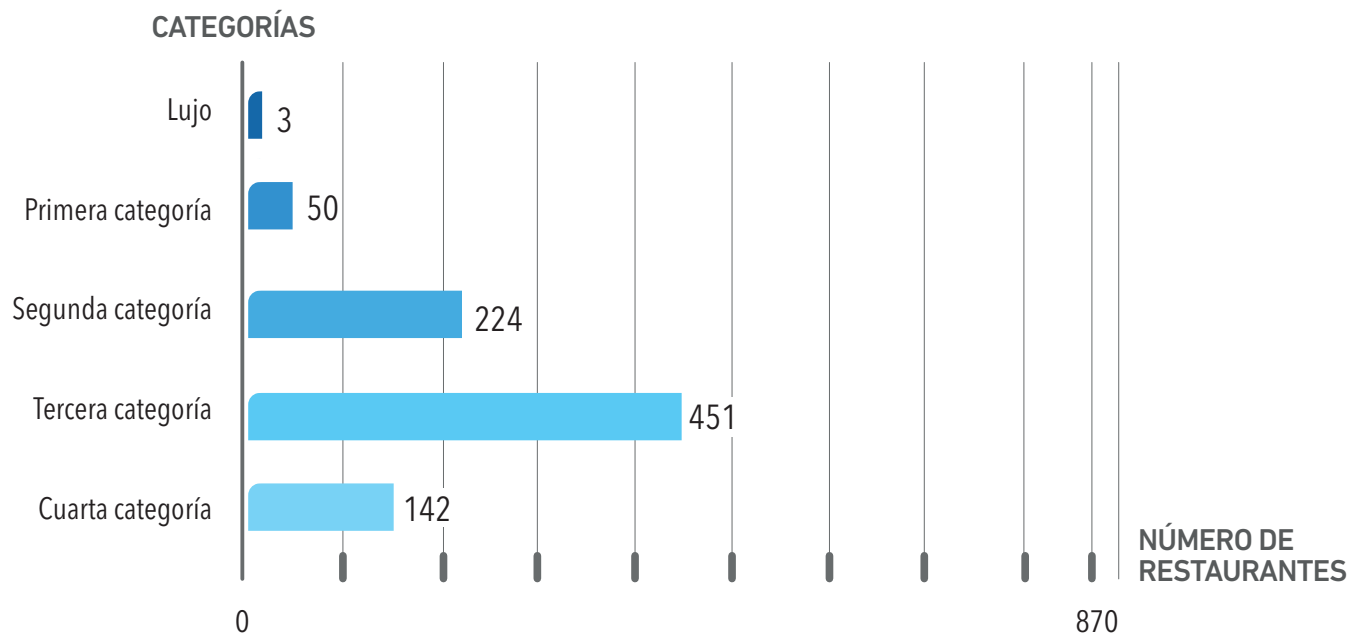

Gráfica 1. Número de restaurantes de la ciudad de Cuenca. (Elaboración propia).

Fuente: Ministerio del Turismo (2018).

\section{Problemática}

La mayoría de administradores de establecimientos gastronómicos buscan atraer clientes centrando todas sus acciones en ofrecer productos deliciosos y de calidad. Al concentrarse en esto, algunos propietarios de restaurantes olvidan dar a conocer las características de sus productos, demostrar cómo actúan y como favorecerán al consumidor. Es decir, no plantean la estrategia comunicacional y por ende olvidan la comunicación gráfica.

Por otro lado, muchas veces las comunicaciones, tanto escritas como gráficas, no están correctamente planteadas y no ofrecen una adecuada diferenciación con la competencia. El identificador 0 logo y los soportes gráficos no son consistentes o no refuerzan adecuadamente el mensaje 0 identidad de la marca. Los colores, la tipografía, los materiales, las imágenes no complementan de manera adecuada a la imagen del establecimiento.
En la presente investigación se han identificado algunas debilidades del sector gastronómico:

- Desconocimiento de los propietarios y del personal del restaurante sobre los beneficios que el diseño gráfico y el marketing pueden generar para atraer más clientes.

- Mal estado y falta de atractivo visual en las cartas o menús.

- Letreros en mal estado o poco visibles.

- Falta de aseo en los utensilios y espacios del restaurante.

- Poca amabilidad y buen trato del mesero hacia los clientes.

- Un pequeño porcentaje de restaurantes, 36,84\%, tiene alguna certificación de la Cámara de Comercio de Cuenca, Trip Advisor, etc. 


\section{Metodología}

La presente investigación está compuesta por un estudio cualitativo y otro cuantitativo, cuyo objetivo es proponer cómo el diseño gráfico se puede configurar tomando en cuenta la información proveniente de una estrategia de marketing propuesta para los restaurantes de primera categoría de la ciudad de Cuenca.

El primer paso fue proponer, a través de un estudio de mercado que analizó la oferta gastronómica de la ciudad, un modelo para el manejo de las variables de marketing mix: precio, producto, promoción, posición, presencia física, personas y procesos, y se determinó que está compuesta por clientes que buscan conocer la cultura de un pueblo, relacionarse con similares y vivir experiencias sensoriales en ambientes estimulantes mediante acciones y emociones.

El segundo paso es, considerar los resultados del estudio de marketing para configurar las acciones de diseño gráfico que apoyen y fortalezcan la imagen y las comunicaciones de los establecimientos gastronómicos, sobre todo en los que se refiere a promoción y presencia física.

En la investigación cualitativa, se obtuvo información de una revisión bibliográfica, de entrevistas y observación directa estructurada. En cuanto a la investigación cuantitativa, se aplicaron encuestas a un grupo de clientes de 19 restaurantes de primera categoría de la ciudad de Cuenca. Para determinar la muestra de restaurantes estudiados y el número de clientes encuestados en cada uno, se aplicó el método de saturación, en el que inicialmente se busca un participante y de acuerdo con la información que se obtiene, se buscan más participantes hasta llegar a un punto de saturación; es decir, se recoge información hasta que se llega a un momento en el que ya no se obtiene nueva información.

\section{Investigación cualitativa} Revisión bibliográfica
Flavián (2011), expone que los restaurantes de primera categoría deben establecer precios competitivos no excesivamente altos; utilizar productos locales como materia prima para la preparación de los platos, resaltando la zona geográfica de origen de los mismo y colocar sucursales en puntos estratégicos de la ciudad.

Jurado (2014) expresa que la recomendación de amigos o familiares, conocido como el "boca a boca" es la principal fuente de promoción; así como el "boca-oído electrónico" que se da en la red a través de fotos, videos y comentarios. Además, los restaurantes deben emplear el comercio electrónico y mantener una comunicación post compra.

Por su parte, Estrella y Segovia (2016) aseguran que es necesario integrar las diferentes herramientas de comunicación dentro del establecimiento realizando una mezcla promocional de publicidad, promoción de ventas, relaciones públicas, ventas personales y herramientas de marketing directo. Gibson (2007) recomienda que los restaurantes deben fusionar los elementos tradicionales de comida, servicio y arquitectura con el diseño gráfico para dar lugar a una experiencia inolvidable.

También se deben estandarizar los procesos del salón y de la cocina. La apariencia de los empleados debe ser pulcra, deben ser muy cordiales y educados y manejar otros idiomas, principalmente el inglés. El principal aporte de la revisión bibliográfica está en el empleo del marketing sensorial para ofrecer a los comensales un ambiente estimulante para los cinco sentidos.

Asimismo, Jurado (2014) sugiere que se cree una marca que defina la identidad del restaurante y se agregue valor al relacionar el servicio con el medio cultural, humano y ambiental. El diseño gráfico y el marketing cada vez van más de la mano. Hoy en día no solo basta con que la información este bien planteada, sino también se debe tener un buen diseño gráfico para llegar con el mensaje de forma más efectiva al mercado meta. 


\section{Entrevistas}

Se realizaron 19 entrevistas en restaurantes de primera categoría, las mismas que estuvieron basadas en las $7 p$ del marketing de servicios y en las variables del análisis del sector gastronómico. Los objetivos de las entrevistas fueron:

- Determinar el nivel de conocimiento que se tiene en el establecimiento sobre marketing de servicios

- Conocer las estrategias de marketing que el restaurante utiliza

- Identificar el factor de marketing clave en el restaurante

Para esto, se realizaron las siguientes preguntas:

- ¿Ha tenido alguna limitación política, legal, social o cultural para el desarrollo de su actividad?

- ¿Cómo emplea la tecnología en los procesos y servicios?

- ¿Qué entiende usted por marketing de servicios?

- ¿Cuáles son las estrategias de marketing que se emplean en el restaurante?

- ¿Su servicio está representado por alguna marca?

- ¿El establecimiento cuenta con alguna certificación? (TripAdvisor, Municipalidad de Cuenca, etc.)

- ¿Cuál es el factor de marketing que usted cree que es la fortaleza del establecimiento? (comida-bebida, el servicio, la atención y presentación de los empleados, el precio, el valor agregado del restaurante, las instalaciones, la comunicación con los clientes, el servicio post venta, los horarios y la publicidad)

Las entrevistas se desarrollaron en los siguientes restaurantes:
1. La Casa del Marisco

2. Doña Charito

3. Dos Sucres

4. Papa Jhon's

5. Burguer King

6. Los Molinos del Batán

7. El Mercado

8. Puerto Monje

9. La esquina

10. La Casona del Puente Roto

11. La Herradura Milenium Plaza

12. La Herradura Remigio Romero

13. Papardelle

14. Noe Sushi Bar

15. Rancho Chileno principal

16. FogoMar

17. Sakura

18. La Pérgola

19. Los Cebiches de la Rumiñahui

\section{Resultados de las entrevistas}

En base a las entrevistas realizadas, se supo que la comida y el servicio son las fortalezas de los restaurantes de primera categoría en la ciudad de Cuenca. También se pudo complementar la problemática de la investigación con la información obtenida. Finalmente, se descubrió que las personas encargadas de los restaurantes no manejan adecuadamente el diseño gráfico ni el marketing de servicios y no se utilizan estrategias de marketing suficientes para explotar el potencial del establecimiento.

\section{Observación directa estructurada}

El objetivo de la observación directa fue determinar los factores que los clientes consideran para elegir un restaurante de primera categoría. La ficha empleada para la observación se muestra en la llustración 1. 
FICHA DE OBSERVACIÓN

\section{RESTAURANTE}

DIRECCIÓN

FICHA DE OBSERVACIÓN

ESCALA DE CALIFICACIÓN: E = Excelente $\mathbf{B}=$ Bueno $\mathbf{D}=$ Deficiente

\begin{tabular}{l|l|l}
\hline VARIABLES & CALIFICACIÓN & OBSERVACIÓN \\
\hline $\begin{array}{l}\text { Comida - bebida } \\
\text { (Frescura, cantidad adecuada, variedad, } \\
\text { calidad de presentación) }\end{array}$ & \\
\hline $\begin{array}{l}\text { Servicio } \\
\text { (Tiempo de espera, pedido completo y }\end{array}$ & \\
correcto) & \\
\hline Empleados & \\
(Cortesía, dispuestos a ayudar, lenguaje claro, & & \\
aspecto pulcro) & & \\
\hline Precio & & \\
(Calidad - precio, descuentos, promociones, & & \\
formas de pago) & & \\
\hline Valor agregado & & \\
(Playground, espectáculos de música, & \\
eventos, otros) & & \\
\hline Instalaciones & & \\
(Localización, sucursales, parqueadero, acceso, & & \\
fachada, higiene, diseño, ambiente interior) & & \\
\hline Horarios & & \\
(Cómodos, extendidos) & & \\
\hline Publicidad \\
(Radio, TV, redes sociales) & & \\
\hline Otros & & \\
\hline
\end{tabular}

Ilustración 1. Ficha de observación. (Elaboración propia). 
En la anterior ficha se puede observar que la escala de calificación está formada por 3 valores: excelente, bueno y deficiente. Se califican las $7 \mathrm{p}$ del marketing de servicios, basándose en parámetros que los restaurantes deben cumplir para que sean considerados como excelente.

\section{Resultados de la observación directa estructurada}

En base a la observación directa estructurada, los factores del marketing de servicios se calificaron como sigue:

- Precio: Bueno

- Producto: excelente

- Posición: excelente

- Promoción: deficiente

- Prueba física: bueno

- Procesos: bueno

- Personas: excelente

También se observó que los restaurantes de primera categoría no ofrecen un valor agregado para los consumidores.

Investigación cuantitativa

Encuesta a clientes

Las encuestas se aplicaron en fin de alcanzar los objetivos siguientes:

- Saber el grado de satisfacción que los clientes tienen con respecto a las variables del marketing de servicios del restaurante (comida-bebida, servicio, precio, empleados, valor agregado, instalaciones, comunicación, horarios y publicidad)

- Conseguir sugerencias para mejorar las variables del marketing
- Definir los factores de éxito del restaurante, de acuerdo a las $7 p$ del marketing de servicios.

La encuesta piloto se aplicó a 28 personas. Con esto, se estructuró un cuestionario definitivo aplicado a 369 clientes de 19 restaurantes de primera categoría de la ciudad de Cuenca. Estos cumplían el siguiente perfil:

- Edad promedio: 30 años

- Nivel socioeconómico: medio a alto

- Tener poder adquisitivo.

En las encuestas se consultó a los clientes sobre las $7 p$ del marketing de servicios: precio, producto, posición, promoción, prueba física, procesos y personas, aplicando el cuestionario de la llustración 2: 
ENCUESTA

¡ERES NUESTRO MEJOR CRÍTICO!

Por favor sírvase responder las siguientes preguntas honestamente. Sus opiniones son muy valiosas para mejorar nuestros servicios.

\section{1. ¿Por qué le gusta este restaurante?}
Comida
Servicio
Variedad de productos
Local/ instalaciones
Ubicación
Otros

\section{2.¿Cómo se enteró de la existencia del restaurante?}
Recomendación
Al paso
Redes sociales
Radio
TV
Otros

3. Califique los siguientes aspectos del restaurante y escriba alguna sugerencia sobre los mismos, en caso de tenerla.
$\mathbf{E}=$ Excelente
$\mathbf{B}=$ Bueno
$\mathbf{D}=$ Deficiente

\begin{tabular}{l|l|l}
\hline ASPECTO & CALIFICACIÓN & OBSERVACIÓN \\
\hline $\begin{array}{l}\text { Comida - bebida } \\
\text { (Frescura, cantidad adecuada, variedad, } \\
\text { calidad de presentación) }\end{array}$ & \\
\hline $\begin{array}{l}\text { Servicio } \\
\text { (Tiempo de espera, pedido completo y correcto) }\end{array}$ & \\
\hline $\begin{array}{l}\text { Empleados } \\
\text { (Cortesía, dispuestos a ayudar, lenguaje claro, }\end{array}$ & \\
aspecto pulcro) & \\
\hline $\begin{array}{l}\text { Precio } \\
\text { (Calidad - precio, descuentos, promociones, }\end{array}$ & \\
formas de pago) & & \\
\hline $\begin{array}{l}\text { Valor agregado } \\
\text { (Playground, espectáculos de música, } \\
\text { eventos, otros) }\end{array}$ & \\
\hline $\begin{array}{l}\text { Instalaciones } \\
\text { (Localización, sucursales, parqueadero, acceso, } \\
\text { fachada, higiene, diseño, ambiente interior) }\end{array}$ & \\
\hline $\begin{array}{l}\text { Horarios } \\
\text { (Cómodos, extendidos) }\end{array}$ & \\
\hline $\begin{array}{l}\text { Publicidad } \\
\text { (Radio, TV, redes sociales) }\end{array}$ & \\
\hline Otros & & \\
\hline
\end{tabular}

GRACIAS POR SU COLABORACIÓN

Ilustración 2. Encuesta. Cuestionario definitivo (Elaboración propia). 


\section{Resultados de las encuestas}

Luego de aplicar las encuestas se determinó que la comida, el servicio y las instalaciones son los aspectos que los clientes más valoran de un restaurante y que el "boca a boca" es la manera más popular por la que los clientes conocen la existencia de un restaurante; además de haberlo conocido en redes sociales 0 al paso. Dicho esto, la experiencia vivida en el local es decisiva para lograr la fidelidad de los clientes y una buena reputación del establecimiento.

Lamentablemente, en general, las estrategias de los restaurantes están orientadas a mejorar el producto, el servicio y a promocionar el local; sin considerar otros factores importantes que potenciarían las $7 p$ del marketing de servicios para atraer y fidelizar más clientes. Esta situación se da como respuesta del restaurante al tratar de satisfacer las preferencias de los clientes, las mismas que van orientadas al producto, el servicio y las instalaciones. Pero, ¿por qué no también agregar valor a otros aspectos que permitan ofrecer una experiencia inigualable que los comensales no olvidarán y quieran regresar al restaurante una y otra vez? Sin duda, se necesita un nuevo modelo de estrategias de marketing para restaurantes de primera categoría de la ciudad de Cuenca para atraer y fidelizar más clientes.

\section{Propuesta de modelo de estrategias de marke- ting para restaurantes de primera categoría}

La creación de un modelo para los restaurantes de primera categoría de la ciudad de Cuenca se basa en las afirmaciones de Bigné, Font \& Andreu (2000), quienes expresan que los establecimientos gastronómicos orientan sus esfuerzos en mejorar el producto; pero actualmente lo que los clientes buscan es vivir experiencias únicas y exclusivas. Cabrera (2013) también argumenta que la creación de experiencias y la implicación sensorial son fundamentales para satisfacer y fidelizar a los clientes de establecimientos gastronómicos. Así, se puede entregar mayor valor al cliente, aplicando estrategias de marketing innovadoras y competitivas relacionadas al aspecto emocional y sensorial de los clientes para brindarles experiencias inolvidables que los atraigan y fidelicen.

Dadas estas premisas y considerando como base la información recopilada en la presente investigación y los estudios realizados y aplicados con éxito por Bigné, Font \& Andreu en Madrid y Cabrera en Buenos Aires se ha construido como punto de partida un modelo de estrategias de marketing que, una vez planteado, servirá para construir un modelo de diseño gráfico como herramienta para fortalecer la imagen de los restaurantes de primera categoría de la ciudad de Cuenca.

Algunas consideraciones a tomar en cuenta para el planteamiento de estrategias de marketing son: la base legal para que el establecimiento inicie actividades y algunos acercamientos teóricos sobre cómo generar experiencias y las principales motivaciones que tienen los consumidores para buscar vivir las experiencias.

\section{a) Base legal}

ARSA -Agencia Nacional de Regulación, Control y Vigilancia Sanitaria - (2014) señala que los requisitos para que un restaurante inicie sus actividades son:

- Cédula de ciudadanía del propietario o representante legal del establecimiento.

- Registro Único de Contribuyentes (RUC) RISE)

- Categorización emitida por el Ministerio de Industrias y Productividad

- Categorización del Ministerio de Turismo

- Local comercial

- Insumos necesarios para la cocina, el salón y diferentes ambientes

- Permisos de funcionamiento: - GAD Municipal del cantón Cuenca 0 Letrero o Uso del suelo (Predio) o Bomberos - Agencia Nacional de Regulación, Control y Vigilancia Sanitaria -ARCSA- 
o Intendencia

o Ministerio de Turismo

o Servicio de Rentas Internas del Ecuador

Además, cumplir los parámetros del Ministerio de Turismo nombrados anteriormente para instalaciones, servicios y personal.

b) La creación de experiencias a través de cinco vías

Cabrera (2013) afirma que se puede crear una experiencia única para el cliente y fidelizarlo mediante cinco vías:

- Sensaciones: ofrecer sensaciones multisensoriales para crear una experiencia perdurable y un recuerdo positivo.

- Emociones: alejar al cliente de su realidad diaria ofreciéndole una experiencia única que traslade la cultura y vivencias de todo un pueblo a la propuesta gastronómica.

- Pensamientos: recrear épocas pasadas 0 personajes ilustres de la localidad con la arquitectura y ambientación del restaurante.

- Acciones: involucrar a los clientes en los procesos del restaurante, por ejemplo, ellos pueden preparar sus propios platillos bajo la inspección de los chefs. También visitar cultivos del restaurante donde puedan cosechar los productos que servirán de materia prima para elaborar los platos que consumirán.

- Mediante las relaciones: organizar eventos en el restaurante en donde los consumidores interactúen entre sí, por ejemplo, tener cenas específicas cada semana en donde los clientes preparen juntos los alimentos que se servirán.
Estrategias de marketing recomendadas para los restaurantes de primera categoría de la ciudad de Cuenca

En el sector gastronómico se pueden aplicar con facilidad diversas estrategias de diseño gráfico y marketing de servicios para crear experiencias exclusivas que generen posicionamiento en el mercado, fidelización y referenciación positiva de los clientes que permitan mantener una propuesta gastronómica a lo largo del tiempo. Mencionados los puntos anteriores del modelo y en base a la información obtenida en la investigación desarrollada, se recomiendan las siguientes estrategias de marketing para los restaurantes de primera categoría de la ciudad de Cuenca: 
VARIABLES DEL

ACCIONES

MIX DE MARKETING

ESTRATÉGICAS

Producto

- Empleo de productos locales para la preparación de platos.

- Contar con huertos propios que los clientes puedan visitar 0 asociarse con agricultores que produzcan cultivos exclusivos para el restaurante.

- Manejar las ventas personales de las CIM: el chef deberá pasear por las mesas y resaltar las propiedades sensoriales u organolépticas de los productos, así como su zona de origen. Deberá hacerlo con rapidez y mucha cautela, para no incomodar a los comensales.

- Ofrecer alimentos de calidad, frescos, sin congelar, con delicioso sabor, presentación buena y exótica, con una buena relación costo-beneficio.

- Ofrecer productos estandarizados; para lo que se debe tener procesos generalizados para ofrecer siempre el mismo producto.

- Decoración del plato.

- Tener menús de degustación.

- Contar con variedad de platos.

- Emplear utensilios y vajilla de calidad.

- Brindar porciones adecuadas.

- Elaborar platillos con productos sustitutos, por ejemplo, alimentos libres de gluten, bebidas sin dulce, etc.

Precio

- Competitivos.

- Establecer precios elevados sólo si se ofrece una experiencia única e irrepetible.

- Descuentos y promociones frecuentes.

Posición

- Establecer sucursales en puntos estratégicos.

- No contar con servicio a domicilio, pues el modelo se basa en brindar experiencias dentro del restaurante.

- Abrir el local todo el día, los 7 días de la semana.

- Contar con un programa comunicativo consistente que tenga un mismo objetivo estratégico que guíe la promoción del restaurante; es decir, integrar la publicidad, promoción de ventas, relaciones públicas, ventas personales y herramientas de marketing directo.

- Emplear medios electrónicos: redes sociales (Facebook e Instagram), páginas web, Tripadvisor, etc.

- Emplear el marketing directo: estar atento a las necesidades del cliente. Tener una comunicación post compra a través de llamadas, encuestas, correos electrónicos personalizados, redes sociales. Así se tendrá una retroalimentación sobre la percepción del servicio recibido. Contactar al cliente anticipadamente a la llegada de un acontecimiento especial para ofertarle la oportunidad de celebrar aquel evento dentro del restaurante.

- Manejar las relaciones públicas: valorar todo tipo de quejas, escuchar cliente y ofrecer disculpas si fuera necesario.

- Ofrecer promociones constantes.

- Brindar una experiencia inigualable al cliente para que se genere el "boca a boca". 
- Ganar prestigio a través del boca-oído electrónico que se desarrolla en la red con videos, fotos y comentarios.

- Empleo del comercio electrónico o virtual para realizar compra 0 ventas con las estrategias B2C (Negocios a Consumidores).

- Definir la identidad del restaurante con el desarrollo de una marca.

- Ofrecer eventos llamativos dentro de las instalaciones.

Prueba física o evidencia
- Marketing sensorial: brindar un ambiente estimulante para los cinco sentidos, donde el gusto y el olfato sean estimulados por la comida; la vista y el tacto, por la disposición de los elementos en la mesa y el diseño y decoración de todo el local y activar el oído con música.

- Emplear evidencias sutiles que mediante vivencias y detalles hagan que el cliente recuerde que está en un determinado restaurante, por ejemplo, emplear cubiertos grabados con la marca del restaurante.

- Cuidar la presentación física de la carta, usando un material resistente que no se deteriore fácilmente.

- Cuidar el orden y aseo de los utensilios y los espacios.

- Contar con mayor número de parqueaderos.

- Adecuar las instalaciones de modo que sean de fácil acceso y movilización para personas con discapacidad.

Procesos

- Definir estándares máximos y mínimos de tiempo en todos los procesos.

- Brindar mantenimiento preventivo periódico a los utensilios que se emplean para la prestación del servicio.

- Realizar reservaciones y respetar los lugares fijados.

- Estandarizar los procesos para siempre ofrecer la misma experiencia.

- Coordinar los 3 procesos del restaurante: procesos del salón, de la cocina y administrativos.

- Tomar la orden luego de máximo 5 minutos de llegados los clientes.

- Ser más ágiles en el tiempo de servicio.

- Comprobar que los pedidos sean correctos y completos antes de servirlos.

- Tener el número de empleados necesarios, para dar una atención oportuna.

Personas Ventas personales de las CIM:

- El personal debe conocer bien el menú y sus componentes.

- Los empleados deben cuidar su higiene y presentación personal, usar uniforme, manejar una imagen sencilla, sin adornos muy llamativos.

- El personal debe ser educado y detallista con los clientes.

- Adecuado manejo del lenguaje corporal: sonreír oportunamente, fijar la mirada en el interlocutor y controlar los movimientos corporales.

- Ofrecer al cliente un trato personalizado, por ejemplo, llamarlo por su nombre.

- Dominar otros idiomas, especialmente el inglés.

Tabla 1. Manual para el empleo de estrategias de marketing en los restaurantes de primera categoría de la ciudad de Cuenca. (Elaboración propia a partir de los datos obtenidos en la investigación cualitativa y cuantitativa). 
Indicadores de medición del modelo propuesto.

"Todo lo que se puede medir, se puede gestionary se puede mejorar" (Domínguez y Muñoz, 2010, s.p.).

Se debe demostrar numéricamente los resultados del área de diseño y marketing para justificar la importancia de su existencia, por lo que es necesario el uso de métricas. "Una métrica es un cálculo entre magnitudes que tienen cierta relación (...) se deben diseñar y emplear en función de las estrategias de la empresa" (Domínguez y Muñoz, 2010, s.p.). Así, para comprobar el éxito en la aplicación del modelo planteado en la presente investigación, se podrán emplear las siguientes variables:

- Métrica de eficiencia del modelo

- Métrica de eficacia del modelo

- Métrica de actividad

- Rentabilidad del modelo

- Satisfacción

- Retención

- Tasa de reclamos

- Tasa de adquisición

\section{Métrica de eficiencia del modelo}

Analiza los gastos o costes presupuestados para la implementación del modelo. El valor de este indicador debe ser igual o mayor a 1; sino, el restaurante estaría perdiendo eficiencia.

$$
\underset{\text { Eficiencia }}{\text { del modelo }}=\frac{\text { Gastos previstos para el modelo }}{\text { Gastos reales del modelo }}
$$

\section{Métrica de eficacia del modelo}

Mide el cumplimiento de los objetivos formulados mediante la gestión del modelo. Esta métrica debe ser igual o menor a 1; caso contrario, el modelo no estaría generando el beneficio deseado.

$$
\underset{\text { del modelo }}{\text { Eficiacia }}=\frac{\text { Beneficio previsto }}{\text { Beneficio real }}
$$

\section{Métrica de actividad}

Muestra el aumento o disminución en las ventas con relación a un periodo anterior; esto es antes y después de la implementación del modelo propuesto.

$$
\text { Actividad }=\frac{\text { Ventas } n-(\operatorname{ventas} n-1)}{\operatorname{Ventas} n-1}
$$

\section{Rentabilidad del modelo} modelo.

$$
\text { Indica el retorno del dinero invertido en el }
$$

$$
\begin{aligned}
& \mathrm{ROI} \text { del } \\
& \text { modelo }
\end{aligned}=\frac{\text { Beneficio del modelo }}{\begin{array}{c}
\text { Inversión realizada en la } \\
\text { implementación del modelo }
\end{array}}
$$

\section{Satisfacción}

Las encuestas de satisfacción del cliente son la forma más fácil y económica de conocer el nivel de satisfacción del consumidor. Sin embargo, también se puede emplear la fórmula:

$$
\begin{aligned}
& \text { Grado de }=\frac{\begin{array}{l}
\text { clientes que han consumido } \\
\text { en el periodo - clientes que se } \\
\text { han mostrado insatisfechos }
\end{array}}{\text { satisfacción }} \\
& \text { clientes totales en el periodo }
\end{aligned}
$$

\section{Retención}

Hace referencia al número de clientes que vuelven a consumir en el restaurante.

$$
\begin{aligned}
& \text { Tasa de } \\
& \text { retención }
\end{aligned}=\frac{\begin{array}{l}
\text { Número de clientes retenidos } \\
\text { o renovados en el periodo }
\end{array}}{\text { Número de clientes en el periodo }}
$$


Tasa de reclamos

La insatisfacción del cliente se puede identificar en las quejas y reclamos que este presente. Es así que, a menor número de reclamos, mayor satisfacción del cliente.

$$
\begin{aligned}
& \text { Tasa de } \\
& \text { reclamos }
\end{aligned}=\frac{\text { Número de reclamos }}{\text { Número total de personas atendidas }}
$$

\section{Tasa de adquisición}

Expresa el número de nuevos clientes en un periodo determinado. En este caso, el momento posterior a la implementación del modelo.

$\begin{aligned} & \text { Tasa de } \\ & \text { adquisición }\end{aligned}=\frac{\text { Número de clientes nuevos en el periodo }}{\text { Número de clientes en el periodo }}$
Sugerencias de diseño gráfico para fortalecer la aplicación del modelo de marketing en restaurantes de primera categoría

El diseño gráfico se ha fortalecido debido a la presencia de nuevos canales de comunicación visual como el internet, las aplicaciones y las redes sociales, ya que éstos constituyen medios de gran utilidad para promocionar una marca 0 un restaurante. La identidad de marca debe reforzarse en todos los soportes y piezas que se diseñen.

Estas recomendaciones se han elaborado según los requerimientos gráficos de las estrategias de marketing planteadas anteriormente, y se constituyen en acciones que potencian la efectividad de dichas estrategias. Están basadas, también, en estudios previos de Mielnikowicz (2017), Pastor (2015), Peralta (2011), Banco Interamericano de Desarrollo (2013) y Rosero (2012).

- Elegir un nombre impactante, que resuma en un "golpe de vista" lo
que se quiere transmitir.
- El nombre debe ser breve, sonar bien, ser único y sugestivo, de fácil
pronunciación y tener connotación positiva.
- Las mejores opciones son los isologos (símbolo y texto) o logotipo
(solo texto).
- Se debe generar un manual de uso de la marca, que muestre las
posibles variaciones de los elementos corporativos.
- Las formas, líneas, imágenes y tipografía utilizadas deben adecuarse a
la identidad del restaurante.
- Se recomiendan los colores cálidos y terrosos.
- Debe proyectar una imagen, es decir, cómo se desea que la gente
reconozca el restaurante: acogedor, divertido, formal, etc.
- El diseño gráfico debe fortalecer a través de sus componentes el
mensaje comunicacional y publicitario.
- El sistema de diseño gráfico debe ser coherente y mantener unidad y
variedad para los distintos soportes tanto impresos como electrónicos.
- Debe resaltar a través del color, la tipografía y la fotografía las distintas
promociones y llamar la atención del consumidor
• Toda la identidad del restaurante se debe traducir a formas, colores,
tipografía y debe ser constante en las distintas comunicaciones gráficas
del establecimiento.


- El diseño del letrero se debe integrar a la imagen del restaurante.

- La materialidad y construcción también debe ser acorde al concepto de marca.

- El letrero debe colocarse en una parte visible del exterior del establecimiento.

- Según la normativa municipal del cantón Cuenca, el tamaño del letrero debe ser el $5 \%$ de la pared en donde va a emplazarse el letrero (Municipalidad de Cuenca, 2004).

- Los textos deben ser legibles, sin uso de fondos que dificulten la lectura.

- Combinar máximo dos tipografías, que tengan variaciones de estilos (roman, itálica, negrita, etc.) y con un tamaño de letra adecuado, se recomienda mínimo 12 puntos.

- Las cartas pueden llevar tipografía e imágenes. depende del tipo de establecimiento.

- La información se organiza por categorías, entradas, platos fuertes, postres, bebidas, otros.

- Se deben organizar los ítems de acuerdo al recorrido del ojo al leer el menú, siempre los productos con mayor rentabilidad van a la derecha arriba.

- La portada debe destacar el nombre del restaurante.

- Las páginas interiores deben ser atractivas, para garantizar la atención de los consumidores.

- Se puede usar cuatricromía o duotono.

- El formato dependerá del tamaño de la mesa. Menús plegables son aptos para mesas pequeñas.

- La elección del papel no es solo una cuestión de imagen, sino de higiene y uso. Se recomiendan los materiales lavables para las portadas y poco porosos para los interiores.

- El diseño gráfico de la carta, debe cuidar el uso de los materiales. Pero además debe cuidar de los siguientes detalles, que Grep Rapp (2016), ingeniero en diseño de menús, recomienda para su diagramación:

- Remarcar los platos "estrella" con un recuadro, sombreado, siempre ayuda a incrementar las ventas.

- Describir los platos evocando productos y marcas de calidad o elaboraciones tradicionales.

- Colocar los precios a continuación del nombre del plato, sin el símbolo de moneda, y sin alinear todas las cifras, nos ayudará a que el cliente no se fije mucho en el precio del plato.

- En un menú de una sola hoja, el cliente fijará su atención en la parte superior, si tienen dos hojas, la parte superior de la derecha será la que tenga un mayor protagonismo.

- Las imágenes deben reflejar la esencia del local, su estilo y su identidad, muestran los productos ofrecidos en el establecimiento, se debe mostrar siempre productos locales, frescos y con buena presentación.

- Las fotografías deben ser tomadas por un profesional.

- Si son fotografías de platos, la imagen debe despertar el interés y el apetito.

- Las fotografías de producto deben ser individuales, no es recomendable mostrar grupos de productos. Se debe utilizar fotografías de platos terminados, con buena iluminación y claridad, cada fotografía debe ir acompañada de una descripción mínima. 
- Cuidar los detalles, el color de las salsas, la textura de las carnes, los brillos. La comida debe tener un tratamiento de food styling.

- Deben ser fotografías de estudio o panorámicas.

- Efectuar un trabajo retoque digital, mejorar el brillo y el contraste, otorgar calidez.

- La resolución de la imagen debe ser de al menos 300 DPI.

- Siempre se debe contar con fotografías del local vacío y con clientes, cada producto emplatado, la actividad en la cocina, el personal de servicio, actividades y eventos, los clientes disfrutando del restaurante.

Publicidad

- Siempre será recomendable del desarrollo de un brief, si no se cuentan con los recursos para desarrollarlo, por lo menos se debe tratar de entender quién es el consumidor al que va dirigida la publicidad.

- El diseño gráfico de la publicidad debe ser muy atractivo y de gran impacto.

- Se deben usar imágenes de primer plano de los platos o de otros productos.

- En los anuncios con los que el cliente tiene más tiempo de contacto se recomienda manejar la siguiente estructura: encabezado con la promesa del beneficio, explicación de la promesa, explicación de la propuesta, un respaldo de garantía como una fotografía, una invitación a la acción y la información de contacto (Valllsmadella, 2002).

- Dentro del diseño gráfico se debe proponer el uso de un código QR, sobre todo en los formatos impresos, que direccione a aplicaciones como Google Maps para indicar la ubicación del local.

Papelería

Corporativa
- Las tarjetas de presentación son obligatorias.

- En la actualidad se recomienda únicamente diseñar una hoja membretada, para ser usada en documentos de negocios o administrativos.

- Las facturas, notas de venta, tickets deben llevar la marca y respetar los parámetros de manejo corporativo.

- El material para impresión dependerá del concepto del restaurante.

Redes Sociales

- Se debe contar con excelentes fotografías en alta resolución de los platos y del establecimiento.

- También es necesario contar con fotografías de personas consumiendo los productos.

- El diseño de las publicaciones debe tratar de generar interacción y compromiso.

- La foto de un plato siempre debe tener la descripción del mismo.

- Se debe colocar la información de contacto del restaurante, los horarios de atención, dirección, etc.

- Se deben usar colores adecuados para reforzar lo que se quiere transmitir.

- Tratar en lo posible que los contenidos sean nuevos y muy creativos.

- Siempre se debe incluir el logotipo del restaurante.

- Se deben subir fotos de eventos que se desarrollaron en el restaurante, de visitantes famosos y de nuevos platos que ingresen a la carta. 
Página Web - La página web es obligatoria.

- Debe tener una interfaz sencilla, de fácil navegación y acorde a la

imagen corporativa del restaurante.

- Debe contener varias páginas o secciones.

- El dominio de la página debe contener el nombre del restaurante.

- Siempre debe ser bien cuidada, pulida y estar actualizada.

- Debe contener botones que dirijan a las redes sociales.

- Debe acoplarse a los distintos dispositivos móviles.

Prueba física o evidencia
- Según sea el concepto del restaurante, el diseño gráfico aportará con elementos gráficos que refuercen la sensorialidad del ambiente, sobre todo en el aspecto visual. Se pueden usar fotografías o textos o una mezcla de los dos elementos. El diseñador debe evocar emociones a través de la gráfica.

- A través del manejo de marca, el diseño gráfico presentará los elementos necesarios para generar recordación, se lo puede hacer a través de aplicar en logo en servilletas, cubiertos, platos, cartas y/o demás utensilios de mesa.

- El uniforme del personal debe tener bordado el logotipo y los colores del vestuario deben ser parte de la paleta cromática utilizada para las demás piezas gráficas.

Tabla 2. Sugerencias de acciones de diseño gráfico para potenciar la estrategia de marketing en restaurantes. (Elaboración propia).

\section{Conclusiones}

La gastronomía es un sector muy importante dentro de la industria del turismo y la economía del Ecuador. La ciudad de Cuenca es reconocida por ser un referente turístico y gastronómico del país, por lo que sus servicios deben cumplir estándares altos. Actualmente, los clientes de establecimientos gastronómicos desean productos deliciosos y de calidad; pero también anhelan vivir una experiencia única y memorable.

Para ofrecer una experiencia única que atraiga y fidelice más clientes, es necesario utilizar estrategias innovadoras de diseño gráfico y marketing. Lastimosamente, la mayoría de administradores de los restaurantes de primera categoría no manejan adecuadamente el diseño gráfico ni el marketing; por lo que no se benefician de todo el potencial que el restaurante podría ofrecer al cliente.

Basándose en la investigación realizada, se ha concluido lo siguiente:

- Es fundamental emplear adecuadamente las siete variables del marketing de servicios: precio, producto, posición, promoción, prueba física, procesos y personas y dentro de ellas las Comunicaciones Integradas de Marketing y el marketing sensorial en el sector gastronómico.

- Se considera que la comida, así como el servicio son las fortalezas de los restaurantes de primera categoría en Cuenca.

- Los restaurantes de primera categoría de la ciudad de Cuenca no ofrecen un valor agregado para los clientes. 
- El perfil del cliente de un restaurante de primera categoría de la ciudad de Cuenca es:

o Edad promedio: 30 años,

o Nivel socioeconómico: de medio a alto,

o Tener poder adquisitivo.

- Las variables del marketing de servicios de los restaurantes de primera categoría de la ciudad de Cuenca, de acuerdo a una escala de excelente, bueno o deficiente, se calificarían como:

o Precio: Bueno,

o Producto: excelente,

o Posición: excelente,

o Promoción: deficiente,

o Prueba física: bueno,

o Procesos: bueno,

o Personas: excelente.

- El "boca a boca" es la forma más usual por la que los clientes conocen sobre la existencia de un restaurante. También los conocen al paso o en redes sociales, en donde se analizan las opiniones y la experiencia vivida por los clientes.

- La comida, el servicio y las instalaciones del local son los aspectos más valorados por los clientes.

- La mayoría de estrategias se dirigen al producto, servicio y promoción del local; dejando de lado las otras variables del marketing de servicios (precio, posición, procesos, presencia física y personas).

- Se deben considerar las motivaciones del cliente para vivir una experiencia única e inolvidable. Ellos necesitan seguridad sabiendo que el restaurante tiene buenas prácticas de higiene y manufactura. Por otro lado, el cliente desea interactuar y comunicarse con más gente, saber más sobre la cultura de una civilización a través de su gastronomía y desea activar sus cinco sentidos. Esto se puede ofrecer a través de la creación de sensaciones, emociones, pensamientos y acciones.

- Un restaurante alcanzaría una mayor satisfacción y fidelización de los clientes ofertando experiencias sensoriales y emocionales exclusivas dentro del establecimiento.

- Para la implementación del modelo propuesto, se debe considerar la base legal establecida por el Ministerio de Turismo; así como las motivaciones de los clientes para vivir una experiencia exclusiva y crear estas a través de las sensaciones, las emociones, los pensamientos, las acciones, las relaciones humanas y un empleo adecuado de estrategias de diseño gráfico y marketing de servicios.

\section{Recomendaciones}

- Se debe, en función del presupuesto y de que la gráfica sea planteada de manera efectiva, contratar una agencia de diseño o de un diseñador freelance para que, a través de su trabajo, realmente se potencie y complemente la estrategia de marketing.

- No existe una receta para el planteamiento de la gráfica, todo dependerá del tipo de establecimiento, los clientes, el contexto y concepto que se quiera transmitir. Las recomendaciones dadas desde el diseño gráfico constituyen aspectos básicos o mínimos que se deben tomar en cuenta al momento de plantear una imagen promocional corporativa o publicitaria.

- Implementar el modelo de estrategias de diseño gráfico y marketing propuesto y emplear los indicadores señalados para la medición de los beneficios obtenidos. 


\section{Referencias bibliográficas}

Agencia Nacional de Regulación, Control y Vigilancia Sanitaria -ARSA-. (2014). Guía de Requisitos que se requieren para la Obtención del Permiso de Funcionamiento de los Establecimientos sujetos a Vigilancia y Control Sanitario. Quito: ARSA.

Banco Interamericano de Desarrollo (2013) Manual de orientación para participar en redes sociales. Washington. Obtenido de http://www.etnassoft.com/biblioteca/manual-de-orientacion-para-participar-en-redes-sociales/

Bigné, E., Font, X. \& Andreu, L. (2000). Marketing de destinos turísticos: análisis y estrategias de desarrollo. Madrid: Esic Editorial.

Cabrera, S. (2013). "Marketing gastronómico: La experiencia de convertir el momento del consumo en un recuerdo memorable". Cuadernos del Centro de Estudios en Diseño y Comunicación. Ensayos, (45), pp. 165-174. Obtenido de http://www.scielo.org.ar/scielo.php?scrip$\mathrm{t}=$ sci_arttext\&pid=S1853-35232013000300015\&lng=es\&tlng=en.

Díaz, C. \& Oyarzo, C. (2017). "Alimentación tradicional en la región del Maule de Chile. Representación de clientes y encargados de restaurantes tradicionales". Estudios sociales (Hermosillo, Son.), 27(50). Obtenido de https://dx.doi.org/10.24836/es.v27i50.428

Domínguez, A. \& Muñoz, G. (2010). Métricas del Marketing. España: Esic Editorial. Obtenido de https://books.google.com.ec/books?id=yt3HBAAAQBAJ\&printsec $=$ frontcover\&dq=Indicadores + de + medici\% $C 3 \% B 3 n+$ de + estrategias + de + marketing + propuestas\&hl=es\&sa $=X \&$ ved=0ahUKEwjK7uWj8szbAhVMt1MKHd6BAKkO6AEIJjAA\#v=onepage\&q\&f=false

Estrella, A. \& Segovia, C. (2016) Comunicación Integrada de Marketing. España: Esic Editorial. Obtenido de https://books.google.com.ec/books?id=eoaCCwAAQBAJ\&printsec=frontcover\&dq $=$ comunicaciones + integradas + de + marketing $\& h=e s \& s a=X \& v e d=0$ ahUKEwiE9NeB2-vcAhVQq1kKHSAtCAkQ6AEIJjAA\#v=onepage \&q=comunicaciones\%20integradas $\% 20$ de $\% 20$ marketing\&f=false

Fandos, C. \& Flavián, C. (2011). Turismo gastronómico: estrategias de marketing y experiencias de éxito. Zaragoza: Prensas Universitarias de Zaragoza. Obtenido de https://books.google. com.ec/books?id=N8Y1K2fwCnYC\&printsec $=$ frontcover $\& d q=i m p o r t a n c i a+d e+l a+g a s-$ tronom\%C3\%ADa+en+el+turismo\&hl=es-419\&sa=X\&ved=0ahUKEwjipMLshlbaAhUG 7VMKHYioCpIQ6AEINDAC\#v=onepage \&q\&f=false

Gibson, G. (2007) A la carta. Diseño Gráfico para restaurantes. Barcelona: Gustavo Gili.

Gil, C., Torres, I., \& López, Z. (2013). "Dimensión integral e interdisciplinaria del concepto de comportamiento del consumidor". Anagramas Rumbos y Sentidos de la Comunicación, 11 (22), pp. 179-200.

Gomes da Costa, P. C. (2008): "Escenarios de la geografía: La espacialidad de las imágenes y sus significados". En Z. Rosendhal \& R-L. Correa (Eds.), Espaçao e cultura, pluralidade de tematica (El espacio y la cultura, la pluralidad de temática), pp. 187-209. Rio de Janeiro: UERJ.

Jurado, G. (2014). Calidad de la gestión en el servicio y atención al cliente para el mejoramiento de las operaciones internas en restaurantes de lujo en el centro histórico de Quito. (Tesis de posgrado no publicada). Quito: Pontificia Universidad Católica del Ecuador.

Kotler, P. (2001). Dirección de Marketing. México: Pearson Educación. 
Kotler, P., Bloom, P. \& Hayes, T. (2004). El marketing de servicios profesionales. España: Ediciones Paidós Ibérica S.A. Obtenido de https://books.google.com.ec/books?id=FgSV_iL3pzMC\&pg $=$ PA25\&dq $=$ Las $+7 p+$ del + marketing + de + servicios\&hl $=e s-419 \& s a=X \& v e-$ $d=0$ ahUKEwjDIrG7g4naAhU02FMKH044CLUQ6AEIJjAA\#v=onepage $\& q=$ Las\%207p\%20 del\%20marketing\%20de\%20servicios\&f=false

Kotler, P. \& Armstrong, G. (2007). Marketing. Versión para Latinoamerica. México: Pearson Educación. Obtenido de https://uvgcancun.files.wordpress.com/2016/03/kottler-phillip-armstrong-gary-marketing-versic3b3n-para-latinoamc3a9rica.pdf

Lloret, E. (2012). Desarrollo de un programa de capacitación para el personal de servicio en tres restaurantes de cuenca (Tesis de grado no publicada). Cuenca: Universidad de Cuenca.

Mielnikowicz, M. (2017). "La construcción de la identidad de marca en la gastronomía contemporánea y la influencia en la percepción del consumidor". Revista Turydes: Turismo y Desarrollo, n. 22 (junio 2017). Obtenido de http://www.eumed.net/rev/turydes/22/marca-gastronomia-argentina.html http://hdl.handle.net/20.500.11763/turydes22marca-gastronomia-argentina

Mora, F. (2013). Análisis estratégico de la segmentación de los restaurantes de primera clase, de la ciudad de Cuenca antes y después de la aplicación de los descriptores de Segmentación. (Tesis de grado no publicada). Cuenca: Universidad del Azuay.

Municipalidad de Cuenca. (2004). Reglamento a la ordenanza que regula la instalación y control de la publicidad y propaganda exterior en el cantón Cuenca - Codificado. Cuenca: Ilustre Municipalidad de Cuenca

Pástor, M. (2015). Art \& Food. Imagen corporativa de un gastrobar. Tesis de grado en Bellas Artes. Valencia: Universitat Politécnica de Valencia.

Peralta, P. (2011) Identidad visual corporativa para un Bar - Restaurante de comida oriental. Tesis de grado. Facultad de Artes. Cuenca: Universidad de Cuenca

Pérez, F. J. (2011). "El diseño gráfico: Alimento para la vista". El Nacional Obtenido de https:// search.proquest.com/docview/863073689?accountid $=36552$

Pierini, A. (2011). Importancia del diseñador gráfico en el mercadeo. El tornillo que le faltaba al marketing. Obtenido de: https://www.gestiopolis.com/importancia-disenador-grafico-en-el-mercadeol

Rosero, S. (2012). 100+ herramientas útiles para Community Managers. España. Libro electrónico. Obtenido de http://www.etnassoft.com/biblioteca/100-herramientas-utiles-para-community-managers/

Vallsmadella, J. (2002). Técnicas de Marketing y Estrategias para Restaurantes. Madrid. Pearson Educación.

Withers, J. \& Vipperman, C. (1998). Marketing de servicios: guía de planificación para pequeñas empresas. España: Ediciones Granica S.A. Obtenido de https://books.google. com.ec/books?id=JnifYrxE6bkC\&printsec $=$ frontcover\&dq = marketing + de + servicios\&hl=es-419\&sa=X\&ved=0ahUKEwjahPi1xojaAhWLqIMKHVytAqwO6AEIJjAA\#v=onepage $\& q=$ marketing $\% 20 \mathrm{de} \% 20$ servicios $\& f=$ false 
